\title{
PROACTIVE MANAGEMENT OF BUSINESS CHANGE
}

\author{
Mamadou Camara, Lyes Kermad, Abderrahman El Mhamedi \\ IUT de Montreuil- Université de Paris 8. \\ 140, rue de la Nouvelle France \\ 93100 Montreuil Cedex, FRANCE \\ E-mail: mamadousamba_c@yahoo.fr
}

\begin{abstract}
This paper addresses enterprise performance problems that can occur after Business Process Reengineering (BPR) project as consequence of business change. The general idea is to lean a Bayesian network from past BPR projects and use this model for prediction in future restructured processes. The role of Bayesian network will be to measure influence of business process structural changes, quantified by structural change metrics, and the increasing or decreasing of process performance, quantified by operational variation metrics. The paper's focus is interoperable structural change metrics definition using process ontology, and operational variation metrics definition. Bayesian prediction model learning, application and result interpretation are discussed in (CAMRA, et al., 2007). The method we propose is for use for the validation of enterprise restructuration, more precisely in the validation of business processes restructuration's.
\end{abstract}

\section{INTRODUCTION}

The Business Process Reengineering method (BPR) is described by Hammer and Champy as "the fundamental reconsideration and the radical redesign of business processes, in order to achieve drastic improvement of current performance in cost, services and speed (Hammer, et al., 2003). Information technology like ERP (Enterprise Resource Planning) is a critical enabler of this change (García Díaz, 2004). The risk that users can not answer the changes is one of the most important problems in BPR projects (Tatsiopoulos I. P., 2003) which suffer from low rate of success.

Looking at the research done on risk management in BPR projects, we can find that there is a lack of quantitative methodologies to manage risk related to business change. Mostly, final users' dissatisfaction face to the deepness of change is just cited in risk factors and change management is recommended in success factors (Bernard J., 2002) (Hammer, et al., 2003) (García Díaz, 2004) (Kermad L., 2003) (Bernier, et al., 2003). Some author's like Anderson (Anderson, 2001) have addressed organizational change's impact in BPR projects using quantitative method. His proposition is a Bayesian prediction of the impact of potential changes in organization structure, senior leadership, and strategic vision variables on the decision marking variables. We think that his variables are too global because he is working at the level of the whole enterprise. He also uses a questionnaire to measure 
variables, with the consequence that the variables will not be completely quantitative and completely objective. In (Tatsiopoulos I. P., 2003) also, the application of Monte Carlo simulation is presented for risk related to time, and the author says that a similar approach is proposed for risk related to organizational change without presenting that. We consider that the transposition of this method can not be done automatically because its application varies according to what is analyzed. We've chosen to work in business process level because, according to Garcia (García Díaz, 2004), the unit of analysis in BPR is the business process as opposed to departments or functional areas.

For Bernard (Bernard J., 2002), the business change problem's causes are the gap between as-is and to-be business processes and consequences are deacrese of employes productivity. We propose to define structural change metrics which measure this gap which is the result of change operated on business processes during the BPR. Structural change metrics are extracted from information on processes registered on the process modeling tolls databases. To ensure interoperable metrics not depending on modeling tool, we will use business process ontology to represent our processes. We also define operational variation metrics which represent performance variation between the executions of as-is process and executions of tobe process. A Bayesian model is learned from historical data obtained from past BPR projects. The Bayesian network is a measurable influence relation and prediction model between process performance variation and process structural change. Our contribution is not in the Bayesian network formalism but rather in the definition of the entries of the Bayesian network and the interpretation of the prediction results. The method we propose is for use, as additional criteria, in the validation of the enterprise restructuration, more precisely in the validation of business processes restructuration. Actually, validation criteria are Business/IT alignment and/or performance indicator resulting from simulation of the newly designed process. The paper's focus is interoperable structural change metrics definition using process ontology, and operational variation metrics definition. Bayesian prediction model learning, application and result interpretation are discussed in (CAMRA, et al., 2007).

\section{BUSINESS CHANGE MEASUREMENT}

\subsection{Change metrics definition and data collection}

The structural change metrics we define on business processes are combination of structural metrics (Tjaden, 2001) (Aguilar, et al., 2006A) (Aguilar, et al., 2006B) defined in Business Process Structural Analysis and change metrics (Demeyer, 2000) (Gokhale, et al., 1997) defined in software engineering. Structural metrics are quantification of static properties of business processes (Tjaden, 2001) and represent process structural complexity. In software engineering, Demeyer (Demeyer, 2000) defines change metrics by comparison between successive versions of objectoriented software systems source code. Structural change metrics are extracted by comparison between the AS_is and the To-be version of the business process. This comparison determinates how many units are added and removed for every significant element or relation in the model. To avoid redundancy of data we choose 
to focus the metric definition on the relations between the elements of the process rather-that on the elements themselves. For example for the Relation "Responsible" (An organizational Unit is Responsible of a Function) two metrics are defined. Rmv_Res and Add_Res represent respectively the percent of Removed (only in as-is process) and Added (only in to-be process) relations of type Responsible.

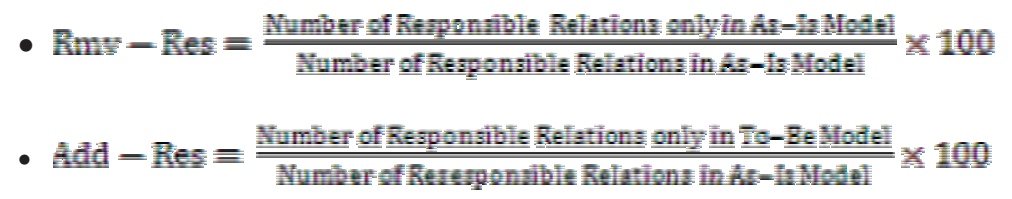

We illustrate change metric calculation through an order processing business process model taken from (Scheer, 1998) in which it is described before and after BPR. These two versions of the business process are depictured in figure 2 and figure3. We have for example, one removed relation of type "Responsible" (PlantOrderPlanning) in a total of three relations of this type. Then the metrics Rmv_Res for this process takes the value $1 / 3$ or $33 \%$.

\subsection{Business Process Ontology and change metrics interoperability}

Business process ontology defines the concepts that constitute a business process and the relationships among them (Jenz, Business Process Ontologies: Frenquently Asqued Questions, 2003B). As such, the business process ontology defines structure. A knowledge base is the result of instantiating ontology, i.e. populating ontology with data (Jenz, 2003A). As such, a knowledge base contains structure and data. Ontology provides terminology interoperability which is the capability to recognize that two pieces of data are talking about the same thing, even though different terminology is being used (Jenz, 2003A). Business process ontology is a machine-readable representation which allows ease and automatic comparison, validation querying and transformation of processes. Business process ontology would describe all concepts related with a business process. In particular it would define entity types such as business activity, business document, business object, business event, business rule, role, resource, and control flow (Jenz, 2003B). Several approaches, techniques and methods have been used to develop enterprise or business process ontology. The best-known are:

- TOVE : Toronto Virtual Enterprise (Kim, 1999)

- Enterprise Ontology (Uschold, King, Moralee, \& Zorgios, 1998)

- BMO Business Management Ontology (Jenz, 2004)

- BPMO Business Process Modeling Ontology (Dimitrov, et al., 2007)

We are interested particularly in BMO (Jenz, 2004) because it is available for free download and is editable using Protégé-OWL. Protégé-OWL (Stanford, 2008) provides a graphical and interactive ontology-design and knowledge-base development environment. Metrics interoperability means in this study that the definition and the extraction of structural change metrics can be performed independently of the business process modeling tool or specification language. To ensure this interoperability we propose the use of business process ontology, the 
$\mathrm{BMO}$ as intermediate representation. For example we can have to constitute a dataset with processes (As-is ad To-be versions) created using ARIS and other processes (As-is ad To-be versions) created using ADONIS. Each concept, and each relation, in the BMO structure (figure 1) have an equivalent class or relation in ARIS and ADONIS meta-models. We translate these process models in process ontology form using two deferent java programs. A third java program will perform the extraction of metrics on all ontological process models in the same manner. For example each function in a process modeled with ARIS will be represented by an instance of the class PrivateProcessTask. We use java because of the existence of Jena java API (Sourceforge, 2008) which enable to handle Protégé-OWL ontology.

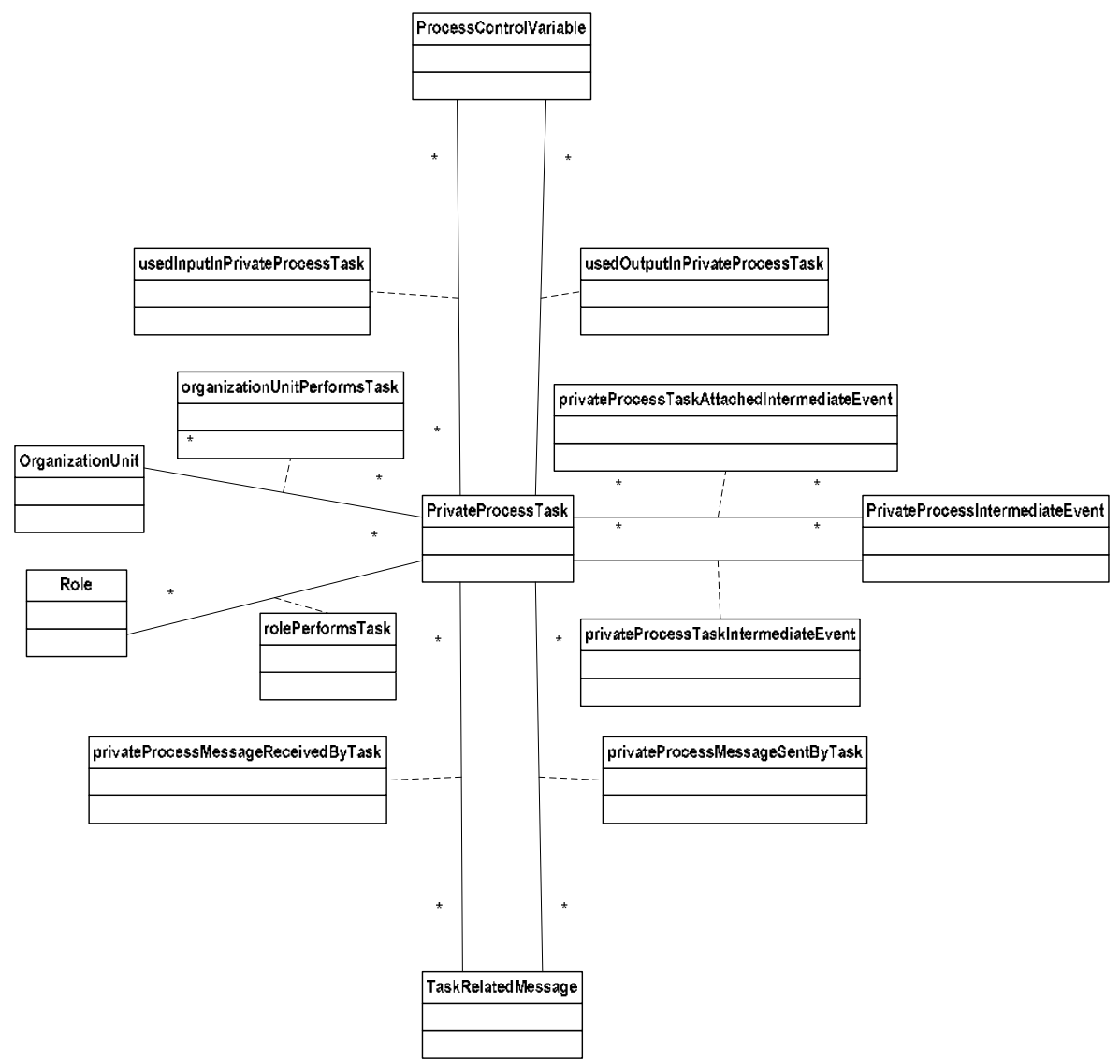

Figure 1BMO structure 


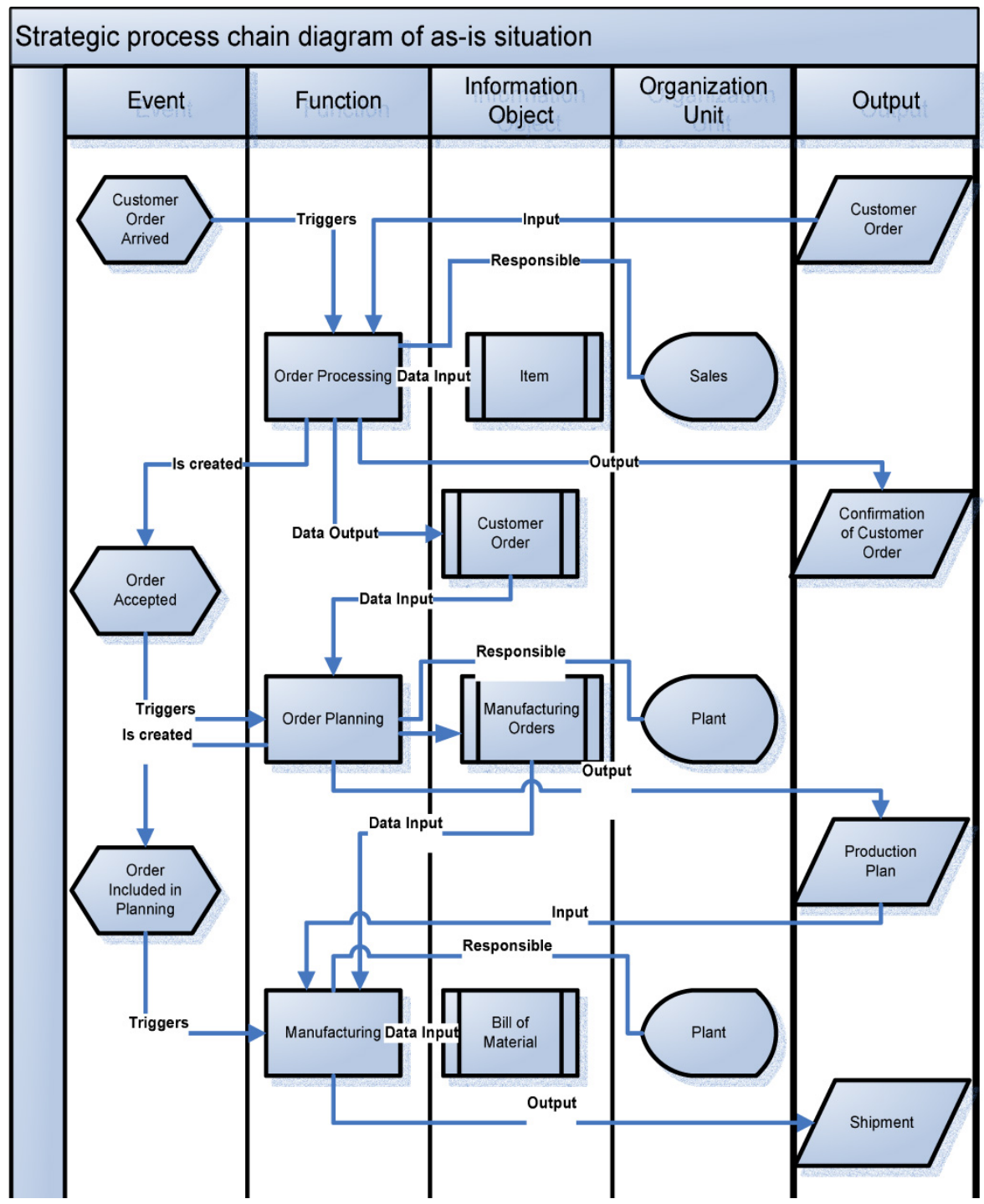

Figure 2 as-is situationof the order processing business process 


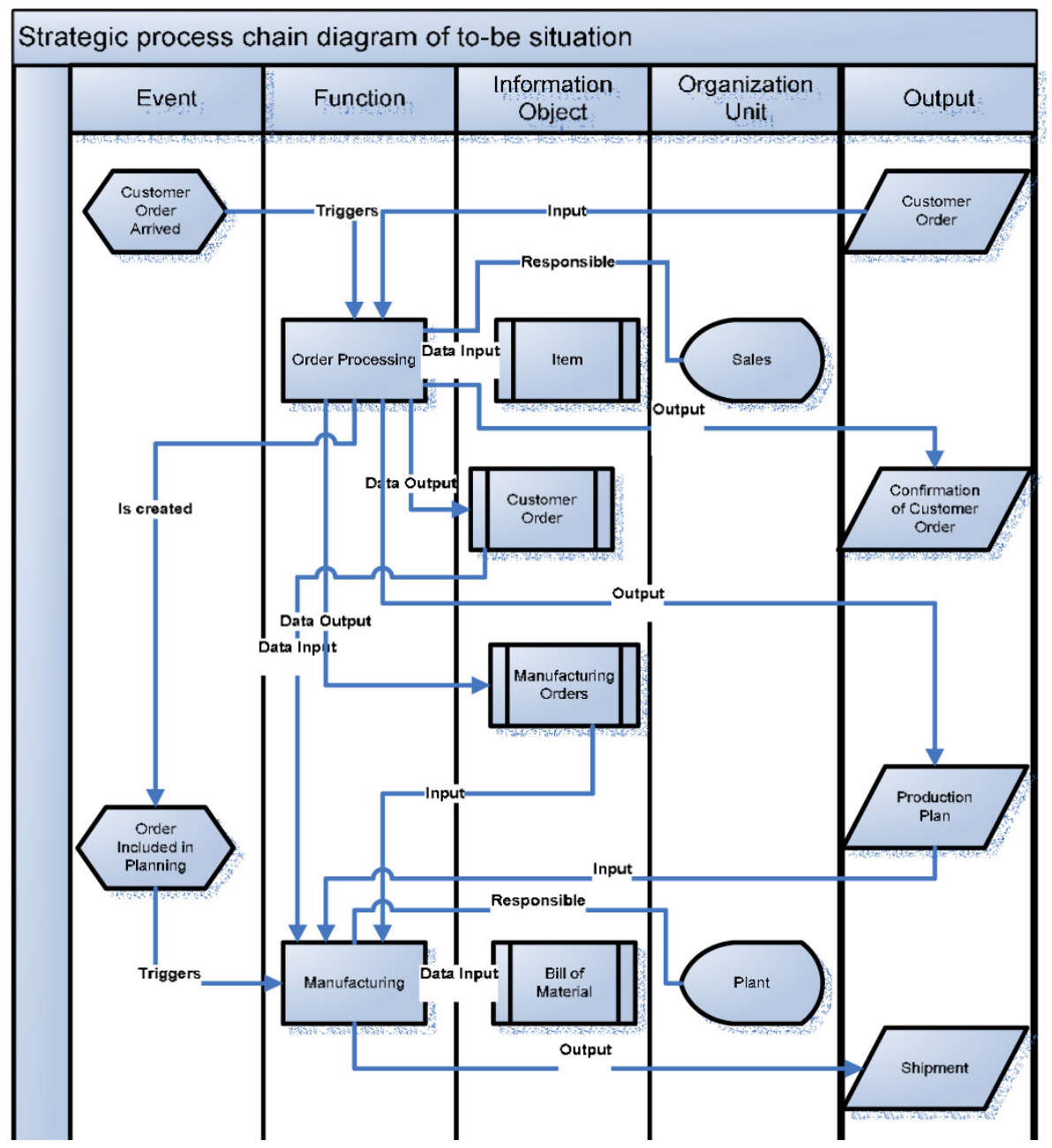

Figure 3 to-be situationof the order processing business process

\section{OPERATIONAL VARIATION METRICS DEFINITION}

Operational variation metrics are also defined; they should represent the process performances variations between the executions before and after BPR. We can find in the literature the following operational metrics:

- Percent manufactured correctly (Tjaden, 2001), fraction (Florac, 1999) or proportion (Baillargeon, 2004) of nonconforming (defective) used in control charts for variables; Average proportion of nonconforming used in control chart p for attributes (Baillargeon, 2004). 
- $\quad$ Process Mean time (Aguilar, et al., 2006A) (Tjaden, 2001), Processing time (Kock, 2001), Cycle time (Kock, 2001), Average time elapsed (IBM, 2008)

- Process cost (Aguilar, et al., 2006A) (Scheer, 1998), average cost of execution (IBM, 2008)

For operational variation metrics extraction the following steps are performed for every process to register in data collection:

1. The As-is process is monitored using BAM (Webmethods, 2006) techniques during a given period

a. Average time elapsed (ATE) metric is calculated

b. Average cost execution (ACE) metric is calculated

c. Fraction nonconforming metric (FNC) is calculated if the characteristic is measurable

d. Average proportion of nonconforming (APNC) metric is calculated if the characteristic is an attribute

2. The To-be process is monitored using same techniques and for a similar period : 1.a, 1.b and 1.c or a.d are performed for the restructured process

3. Operational variation metric are calculated as following

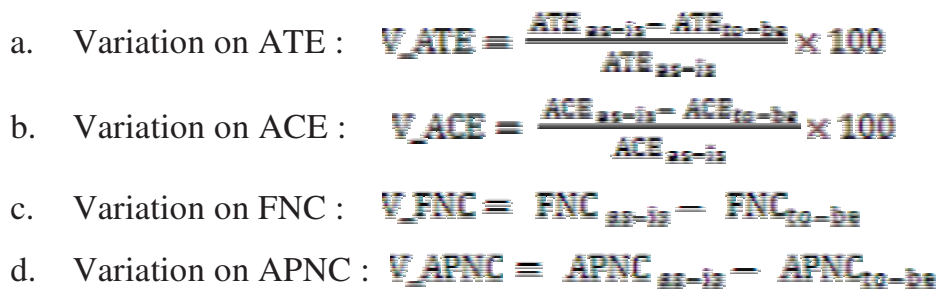

Our proposition consists to the construction of mathematical model using datacollection processes and the application of this model for prediction on other processes. For data-collection processes, structural change metrics and operational variation metrics are extracted. In reality this type of historical data can be held for example by a consulting company having taken part in several BPR projects where it capitalized these data. For processes on which the model is applied only structural change metrics are extracted, in the same way as for data-collection processes, and operational variation metrics are predicted using the model.

\section{CONCLUSIONS}

We propose prediction model to evaluate impact of structural change on process performance, in order to validate process redesign. The principal contribution of this study is structural change metrics and operational variation metric's definition and their use. We've show how business process ontology can help to create interoperable structural change metrics. The final objective of this work is the application of the proposition with a real data set collected on real company processes. 


\section{REFERENCES}

Aguilar E., R. et Ruiz F., Garcia, F., Piattini, M., Evaluation measures for business process model [Conférence] // Symposium on Applied Computing (SAC). - 2006A. - pp. 1567-1568.

Aguilar E.,A. et Ruiz F., Garcia, F., Piattini, M., Applying Software Metrics to evaluate Business Process Models [Revue]. - [s.1.] : CLEI electronic journal, 2006B. - Vol. 9.

Anderson R., D., Lenz, R., T., Modeling the Impact of Organizational Change: A Bayesian Network Approach [Revue]. - [s.1.] : Organizationnal Research Methods, 2001. - 1 : Vol. 4.

Baillargeon G. Statistique Appliquée et Outils d'Amélioration de la Qualité [Livre]. - [s.1.] : SMG, 2004.

Bernard J. Rivard S., Aubert B., Evaluation du risques d'implémentation de progiciel [Rapport] : Gestion intégré des risques / rapport du projet réalisé dans le cadre de l'entente entre Hydro $q u e ́ b e c$, VRQ (Valorisation Recherche Québec) et CIRANO . - 2002.

Bernier C et Roy V. L'évolution des rôles dans la gestion des projets TI : le cas des ERP [Revue]. - [s.1.] : Revue Internationale de gestion, 2003. - 2 : Vol. 28.

CAMRA Mamadou, KERMAD Lyes et EL MHAMEDI Abderrahman PROACTIVE MANAGEMENT OF ORGANIZATIONAL CHANGE USING BAYESIAN NETWORKS [Conférence] // MITIP 2007. - Florence 6-7 September : [s.n.], 2007.

Demeyer S., Finding Refactorings via Change Metrics [Conférence]// the 15 th ACM SIGPLAN conference on Object -Oriented Programming, systems, languages, and applications, 2000.

Dimitrov Marin [et al.] A BPMO Based Semantic Business Process Modelling Environment SBPM 2007.

Florac W., A., Carleton, A., D., Measuring the Software Process: Statistical Process Control for Software Process Improvement [Livre]. - [s.1.] : Addison Wesley Professional, 1999.

García Díaz Martha Liliana A METHODOLOGY TO FACILITATE CONTINUOUS IMPROVEMENT IN THE SERVICES PROVIDED BY THE FACILITIES DEPARTMENT AT UPRM [Rapport]. 2004.

Gokhale S., S. et Lyu M., R., Régression Tree Modeling for the Prediction of Software Quality [Conférence] // ISSAT'97. - Anaheim, CA : [s.n.], 1997.

Hammer Michel et Champy James Le Reengineering [Livre]. - Paris : Dunod, 2003.

IBM Documetation IBM Websphere Business Modeler Advanced // publib.boulder.ibm.com. 2008.

Jenz D., E., Business Management Ontology (BMO) [Rapport]. - 2004.

Jenz, D. E. (2003A). Business Process Ontologies: Frenquently Asqued Questions. Jenz \& Partner $\mathrm{GmbH}$.

Jenz, D. E. (2003B). Business Process Ontologies: Speeding up Business Process Implementation. Jenz \& Partner GmbH.

Kermad L. Roucou P., El mhamedi A., Les conditions de succès d'un projet ERP [Conférence] // 5ème Congrès International de Génie Industriel. - Québec : [s.n.], 2003.

Kim, H. M. (1999). Representing and Reasoning About Quality Using Enterprise Models. Enterprise Integration Laboratory University of Toronto.

Kock Ned Changing the focus of Business process redisgn from activity flow to information flow [Revue]. - [s.1.] : Defense Aquisition Review Journal, 2001.

Scheer A., W., Aris - Business Process Modeling - [Livre]. - New York : Springer Verlag, 1998. - pp. 16

Sourceforge. (2008). Jena A semantic Web Framework for java. Récupéré sur jena.sourceforge: http://jena.sourceforge.net

Stanford, u. (2008). protégé. Récupéré sur protege.stanford.edu: http://protege.stanford.edu

Tatsiopoulos I. P. Panayiotou N. A., Kirytopoulos K, Tsitsiriggos K., Risk management as a strategic issue for the implementation of ERP systems: a case study from the oil industry [Revue]. - [s.1.] : International Journal of Risk Assessment and Management, 2003. - 1 : Vol. 4.

Tjaden G., S., Business Process Structural Analysis [Rapport]/ Georgia Tech Center for Enterprise Systems. - 2001.

Uschold, M., King, M., Moralee, S., \& Zorgios, Y. (1998). The Enterprise Ontology. The Knowledge Engineering Review Vol 13 .

Webmethods Business Activity Monitoring (BAM) The New Face of BPM [En ligne]. - June 2006. http://www1.webmethods.com/PDF/whitepapers/BAM-The_New_Face_of_BPM.pdf. 